\title{
Congenitally Missing Maxillary Lateral Incisors: Update on the Functional and Esthetic Parameters of Patients Treated with Implants or Space Closure and Teeth Recontouring
}

\author{
Núbia Inocencya Pavesi Pini ${ }^{1}$, Luciana Manzotti De Marchi $^{2}$ and Renata Corrêa Pascotto ${ }^{3, *}$ \\ ${ }^{I}$ Department of Restorative Dentistry, State University of Campinas, Campinas, Brazil; ${ }^{2}$ Department of Dentistry, \\ University Center of Maringá - UNICESUMAR, Maringá, Brazil; ${ }^{3}$ Department of Dentistry, State University of Mar- \\ ingá, Maringá, Brazil
}

\begin{abstract}
Maxillary lateral incisor agenesis (MLIA) is a condition that affects both dental esthetics and function in young patients, and represents an important challenge for clinicians. Although several treatment options are available, the mesial repositioning of the canines followed by teeth recontouring into lateral incisors; or space opening/maintenance followed by implant placement have recently emerged as two important treatment approaches. In this article, the current and latest literature has been reviewed in order to summarize the functional and esthetic outcomes obtained with these two forms of treatment of MLIA patients in recent years. Indications, clinical limitations and the most important parameters to achieve the best possible results with each treatment modality are also discussed. Within the limitations of this review, it is not possible to assert at this point in time that one treatment approach is more advantageous than the other. Long-term followup studies comparing the existing treatment options are still lacking in the literature, and they are necessary to shed some light on the issue. It is possible, however, to state that adequate multidisciplinary diagnosis and planning are imperative to define the treatment option that will provide the best individual results for patients with MLIA.
\end{abstract}

Keywords: Agenesis, composite resin, dental agenesis, dental implants, maxillary lateral incisors, orthodontic treatment.

\section{INTRODUCTION}

Maxillary lateral incisor agenesis (MLIA) is the most common congenitally missing permanent tooth condition in the maxillary anterior region (esthetic zone), representing approximately $20 \%$ of all dental anomalies [1-3]. It has been found to be more prevalent in females $[2,4,5]$, and bilateral MLIA are more frequently reported than unilateral cases [6]. Largely, dental agenesis has been attributed to genetic factors [7], but they may also be caused by environmental factors such as dentoalveolar traumas [8], or radiation therapy [9-11]. The susceptibility of maxillary lateral incisors to dental agenesis has been associated with their anatomical position in the maxillary arch and also the fact that they are the last teeth to develop in their respective classes [3].

Patients with MLIA are frequently confronted with functional and esthetic problems at a young age, which may affect their self-esteem and social relationships $[1,12]$ at a sensitive period of their lives (adolescence) [13]. Restoring a balanced dentition requires the formulation of a comprehensive treatment plan. Establishing optimal esthetics, function, and periodontal health in patients with MLIA is a complex and challenging process, which demands the interaction of several dental specialties $[3,14]$. Ideally, the treatment of choice should be the least invasive option to satisfy the expected functional and esthetic objectives [15].

*Address correspondence to this author at the Department of Dentistry, State University of Maringá, Av. Mandacaru 1.550, 87080-000 - Maringá, PR, Brazil; Tel: (55) 44 99820215; Fax: (55) 44 30319051;

E-mail: renatapascotto@gmail.com
Among the options available to the clinician are the possibility of space closure with mesial repositioning of canines, followed by teeth recontouring; or a combination of space opening and prosthetic replacement of the missing lateral incisor [14-18]. Different restorative approaches may be employed in the agenesis area, such as resin bonded fixed partial dentures (FPD), cantilevered FPDs, and conventional full-coverage FPDs. A recent study that assessed five treatment alternatives for maxillary lateral incisor agenesis where space maintenance and tooth replacement were indicated ranked in the following order from most to least costeffective: autotransplantation, cantilever FPDs, resin-bonded FPDs, single-tooth implants and implant-supported crowns, and full-coverage FPDs [20]. However, the primary consideration when deciding which option to choose is the conservation of tooth structure [19]. Other factors such as patient age, the state of the dentition, and occlusion should also influence the choice of the restoration [20]. A recent systematic review performed on the issue [21], concluded that no evidence at this point in time exists for recommending or not recommending one treatment approach for MLIA cases over the other. Thus, clinicians should treat MLIA patients with extreme caution based on their own clinical skills and experience, the clinical conditions of each patient, and patients' expectations [21,22]. Although either treatment approach may be used to achieve predictable esthetics, function, and longevity, if a particular treatment option is not adequate to the individual patient, the final result might be less than ideal. 
The aim of this narrative review of the literature was to describe and discuss the functional and esthetic parameters of patients with MLIA treated either with implants or space closure and teeth recontouring, in order to guide clinicians in their decision making process for the best treatment option with predictable results.

\section{DEVELOPMENT}

A summary of the main parameters involved in the treatment of MLIA patients with space closure followed by teeth recontouring and space opening- maintenance and restoration with implants are displayed in Table $\mathbf{1 .}$

\section{Space Closure and Canine Recontouring}

The treatment of patients with MLIA with orthodontic space closure for the mesial repositioning of the canines and their posterior recontouring into lateral incisors is generally indicated for young patients with malocclusions Class I or II without severe crowding, a balanced or mild-convex profile, and canines of adequate size and shape to be transformed into lateral incisors without the excessive exposition of dentin during the reduction of the cusp and mesiodistal dimensions, and the flattening of the buccal face $[14,23]$. In a recent clinical trial, the majority of patients with MLIA were reported as presenting malocclusion Class II, which is a predisposing factor for the mesial positioning of permanent maxillary canines [19]. In relation to the size of teeth, it has been described that in most MLIA cases, it is common for patients to present smaller teeth than patients without agenesis [24]. According to Fekonja (2013), the reduction in mesiodistal dimensions of teeth of agenesis patients may range from $5-15.5 \%$ in males and $3-15.5 \%$ in females [25]. All these characteristics favour the indication of the treatment with space closure and teeth recontouring.

Due to differences in size, shape and appearance between lateral incisors and canines, different procedures may be indicated to achieve best treatment results $[16,26]$. In relation to shape, lateral incisors are incisiform, with smaller, flatfaced teeth, when compared to the sharp, pointed, and coneshaped canines [27]. This difference should be partially compensated during orthodontic treatment by reducing canine eminence with increased palatal root torque, and the extrusion of the tooth together with its gingival margin $[23,28]$. In relation to size, the cusp and the mesial and distal dimensions of the canines should be reduced before beginning the orthodontic treatment [29]. Finally, canines are normally darker than lateral incisors, and bleaching procedures may be performed to mask differences in color before final teeth recontouring with composite resin $[16,22,29,30]$.

From a functional standpoint, it has been believed for many years that the ideal treatment of MLIA cases would have to result in an Angle Class I molar relationship [31]. The lack of a canine-protected occlusion would also be a disadvantage in cases treated with space closure, which could eventually lead to the occurrence of cervical abfractive lesions in premolars [23,32-34]. Abfractions, as defined by Grippo (1991), are the result of stresses produced by biomechanical loading forces and exerted on the teeth. These forces may be static, as in swallowing and clenching, or cyclic, as in chewing. As a result of the stress caused by static and cyclic forces, both enamel and dentin may chip or break away. How this type of loss of tooth substance manifests depends on the magnitude, duration, direction, frequency, and location of the forces. Abfractive lesions are caused by flexure and ultimately material fatigue, which may affect susceptible teeth even at locations on the dental arch that are distant from the point of loading [35]. However, previous prospective clinical studies have demonstrated that the premolar can be considered a suitable replacement for the canine $[1,31,36,37]$. In agreement with Robertson \& Mohlin (2000) [1], a recent clinical study, showed that no differences in occlusal function, prevalence of cervical abfraction, or signs of TMD symptoms were present in patients treated with space closure and recontouring of the canines [18]. Additionally, the same clinical study also reported that in the majority of cases treated with space closure, canine disclusion (by premolar) was present, and neither canine nor group disclusion were found to be related with TMD [18], corroborating with previous studies $[1,38]$.

In relation to general esthetics, an important point of concern in the reestablishment of a pleasant smile is the width/length ratio of the anatomic crown. This is particularly important in case of patients treated for MLIA, especially when the treatment consists of mesial repositioning of the canines with their posterior recontouring into lateral incisors, as the size of the canine will define the size of the future lateral incisor [39]. In a recent study, Pini et al. (2012) found that patients with bilateral or unilateral MLIA treated with teeth recontouring did not present the same proportionality between the apparent width of the teeth in the smile (central and lateral incisor - lateral incisor and canine) when compared with a control group of patients without agenesis [39]. Teeth width and height of patients treated with recontouring were found to be larger than those of patients without agenesis $[39,40]$. According to the authors, this was attributed to the fact the orthodontic treatment and the conversion of the canines into lateral incisors usually requires the recontouring of other anterior teeth, such as the central incisors, in order to obtain better harmony of the smile $[41,42]$.

Moreover, recent studies [40,43] have also shown that patients treated with canine recontouring presented the zeniths of the replaced lateral incisors predominantly coincident or above the reference line from the zenith of central incisors to canines (Fig. 1). This was explained by the difference between the gingival margin of canines and premolars, in comparison to the teeth they are replacing; the lateral incisors and canines, respectively. In addition to recontouring, it is necessary to orthodontically extrude the maxillary canine and intrude the premolar in order to establish the naturally appearing high-low-high marginal gingival contours of the maxillary anterior teeth [44]. However, some studies have shown that reestablishing the gingival zenith agreeing with the pattern proposed in the literature may not always be possible $[27,40,43]$.

Nonetheless, when laypersons and dentists assessed the attractiveness of the smile of patients with MLIA treated with canine recontouring or implant-supported prosthesis in comparison to untreated controls, using photographs of the lower third of the face, no significant differences were found among any of the groups, suggesting that the treated smile did not have any negative influence on the esthetic 
Table 1. Summary of the main treatment parameters for MLIA patients.

\begin{tabular}{|c|c|c|}
\hline Parameter & Space closure and tooth recontouring & Implant supported restorations \\
\hline Patient age & $\begin{array}{l}\text { Space closure may be performed in younger MLIA patients, } \\
\text { with the use of conservative restorative approaches (resin } \\
\text { buildups or ultra-thin porcelain veneers). }\end{array}$ & $\begin{array}{l}\text { Implant placement should only be performed after the completion } \\
\text { of facial growth (18-19 years for women and 20-21 years for men). }\end{array}$ \\
\hline Occlusion & Group disclusion pattern. & $\begin{array}{l}\text { Possibility of ideal intercuspidation with canine-protected occlu- } \\
\text { sion. }\end{array}$ \\
\hline Gingival architecture & $\begin{array}{l}\text { - Gingival zenith after space closure may not accomplish the } \\
\text { ideal esthetic parameters when the orthodontic treatment is } \\
\text { not adequately performed. }\end{array}$ & $\begin{array}{l}\text { - Implants may provide ideal papilla filling and gingival zenith. } \\
\text { However, these may change over time. } \\
\text { - The progressive loss of marginal bone may result in gingival } \\
\text { discoloration and exposure of implant abutment, which may } \\
\text { compromise esthetics. }\end{array}$ \\
\hline Tooth proportion & $\begin{array}{l}\text { - Canine recontouring results in lateral incisors with altered } \\
\text { width-height ratio in comparison with natural lateral inci- } \\
\text { sors. }\end{array}$ & $\begin{array}{l}\text { - The width of the agenesis area can be orthodontically adjusted. } \\
\text { However, patients may present implant supported crowns higher } \\
\text { than natural lateral incisors. The height of implants will be deter- } \\
\text { mined by the level of the crestal bone and keratinized gingiva }\end{array}$ \\
\hline
\end{tabular}

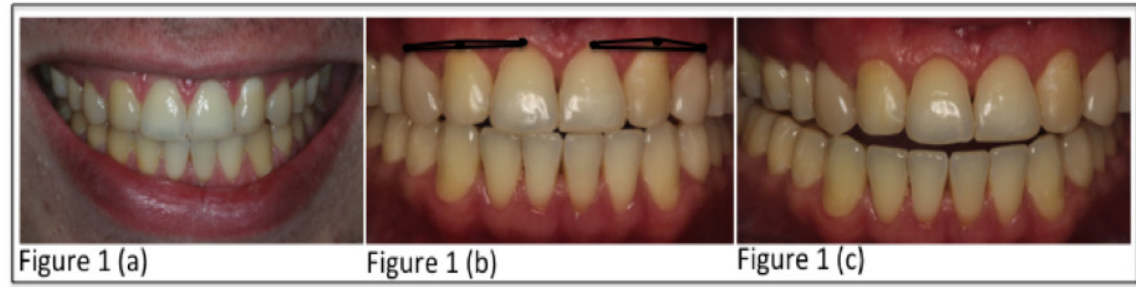

Fig. (1). Patient with bilateral agenesis of the maxillary lateral incisors treated with space closure and recontouring of the canines after 6 years: (a) The smile aspect of the patient; (b) The gingival zenith is marked showing the presence of an inverted triangle, with the canines above the reference line; (c): The functional aspect of the treatment, showing group disclusion.

preference of the evaluators [45]. In another study, however, when intrabuccal pictures of patients were used in a similar analysis, dentists and laypersons rated smiles of patients with MLIA treated with canine replacement as more attractive than those with dental implants [41]. Irrespective of the treatment option for MLIA patients, symmetry [46,47], and absence of diastema in the smile [47] are the parameters most highly ranked by laypersons and professionals (orthodontists and dentists) when assessing smile attractiveness.

It has also been found that patients treated with canine recontouring are more satisfied with the appearance of their smile than patients treated with implants [45]. The reason for that may be in the fact that patients that choose space closure with posterior recontouring of canines into lateral incisors keep their natural teeth in the anterior region instead of receiving prostheses. Additionally, the extended period usually needed to complete facial growth before implant may be inserted, and the additional waiting period for the placement of a definitive prosthesis over the implant, may also have been considered a disadvantage by young patients who completed orthodontic treatment [42].

\section{Implant Supported Restorations}

The treatment of MLIA patients with implants is considered an innovative, more conservative approach, which preserves the morphological features of canines and first premolars, as there is no need to reshape sound adjacent teeth $[3,17,22,48,49]$. The literature presents predictable long-term 
results of MLIA patients treated with implants [3,22,50,51]. In general, the treatment requires space for prosthetic tooth replacement should be orthodontically opened to achieve the adequate space for implant placement. This procedure is often considered advantageous because it permits the maintenance of the canine in its natural position within the dental arch, preserving the ideal intercuspidation (Class I relationship), and a canine-protected occlusion $[16,17,36]$. However, in the long-term, it is not possible to estimate when, to what degree, or in which patients changes in the soft and hard tissues, which could impair patient's esthetics, will occur around implant-supported crowns [44,52]. Faced with this problem, Zachrisson et al. (2011) advocated that, if the treatment plan for young patients includes space opening, it might be preferable to open the space later and place implants in the premolar areas [44].

Space opening for treatment with implants is indicated for patients whose upright maxillary incisors need to be protruded, or tipped labially, to help correct anterior crossbite or to gain upper lip support [16], and to obtain or maintain Angle Class I. Additionally, teeth adjacent to the MLIA should have parallel roots when implants are considered $[16,17,50]$, and implant placement should only be performed after complete facial growth, at around 18-19 years for women and 20-21 years for men [22]. In general, due to the long time required for the treatment with space closure and recontouring of canines, adult patients generally opt for the treatment with implants [18]. For optimal implant placement, it is crucial to create an adequate orthodontic implant site in relation to the space needed, both coronally and apically [53]. Moreover, the dimension of the alveolar ridge, the gingival margin, and the papilla fill are also important aspects to be considered before implant placement [22,53]. The space needed coronally, that corresponds to the space of the lateral incisors to be replaced by the prosthesis, may be determined by measuring the contralateral tooth or, when absent or in a peg-shaped form, based on esthetic proportions, such as the Golden Proportion or the Bolton Analysis [3,22,48,54]. Whatever the situation, the diagnostic wax-up is regarded as the most predictable means to assess the required optimal space [50]. In general, the width of a lateral incisor is about 6-7 mm, which coincides with the minimal mesiodistal space required for a single-tooth replacement. At least $1.5 \mathrm{~mm}$ between the implant platform and the adjacent teeth is required for the development and preservation of the papilla [50,54]. In the apical region, a minimum of $5 \mathrm{~mm}$ is generally necessary to provide sufficient space for a $3.5 \mathrm{~mm}$ implant.

Without the development and eruption of a permanent lateral incisor, the osseous ridge in the agenesis area is typically deficient. The ideal condition, to develop a proper alveolar site with adequate bucopallatal dimension to replace the absent lateral incisor with an implant, is when the permanent canine erupts mesially next to the central incisor $[22,48,54]$. After eruption, the canine can be distalized orthodontically and, therefore, establish a proper buccopalatal alveolar ridge width [53]. Even in this ideal condition, however, changes at the implant site may occur after space opening. Uribe et al. (2013) reported a $17-25 \%$ decrease in bone width at the most coronal measurement of the ridge after space opening, resulting in a reduction of approximately 1.1 mm [55]. In contrast, according to Nováčková et al. 2011, the bone resulting from distalization of the canines in the edentulous site was found to be relatively stable, both horizontally and vertically, over 5 years. The authors reported bone width reduction of just 5\% [51].

The gingival contour and interdental space filling with papilla comprise important aspects in the esthetic perception of the smile [27]. In general, in implant treatments, these aspects are related with the implant position in regard to the gingival margin. In adult patients, the alveolar bone is usually positioned $2 \mathrm{~mm}$ apical to cementoenamel junction, which favors implant placement. In younger patients, however, the alveolar bone is frequently at the level of the cementoenamel junction, which requires the performance of periodontal surgical procedures [53]. In relation to the gingival papilla, space opening is more predictable in young patients. The orthodontic movement provides the formation of two papillae, which will be located at the mesial and distal sides of the implant [54]. Concerning the gingival architecture and the composition of the gingival zenith, the treatment of patients with MLIA with implants showed better results when compared with patients treated with space closure and canine recontouring (Fig. 2) [40,43]. However, progressive infraocclusion in the implant area can occur after some years because of the continuous eruption of adjacent teeth, even in adults and elderly patients [44].

For a long time, the treatment of patients with MLIA with the mesial repositioning and recontouring of the canine was considered the healthiest approach relative to the periodontal status $[17,36]$. As a matter of fact, it has been reported that implant-supported crowns replacing maxillary lateral incisors have shown increased gingival inflammation, increased probing depths, bleeding on probing, and lack of interdental papilla when compared with contralateral natural teeth [56]. In the most recent study evaluating these parameters, which compared patients with MLIA treated with implants or with space closure and canine recontouring with patients without agenesis, it was found that the treatment with implants showed the most significant papilla index alterations; a result that was expected due to the required longterm recontouring of the surrounding soft tissue $[57,58]$

Another possible outcome with the implant technique is the progressive loss of marginal bone support at the buccal aspect of the implant [52]. This ongoing buccal bone resorption can result in discolored soft tissue, gingival retraction, and abutment exposure [22]. However, with the use of switch-design implants with narrow diameters or platforms, the effects of bone remodeling may be minimized [59]. Besides, with the new advances in customized zirconia components, all-ceramic implant-supported restorations may be used to replace absent lateral incisors, reducing the esthetic impact in cases the tissue around implants shift positions over time [22].

From an esthetic point of view (Fig. 2), patients treated with implants presented similar mean teeth width values, but divergent height values when compared to patients without agenesis $[39,40,43]$. This is due to the natural limitation of the implant technique, in which the height of the implant will be determined by crestal bone level and the thickness of keratinized tissue of the gingiva around the implants. These aspects may vary depending on several different aspects such 


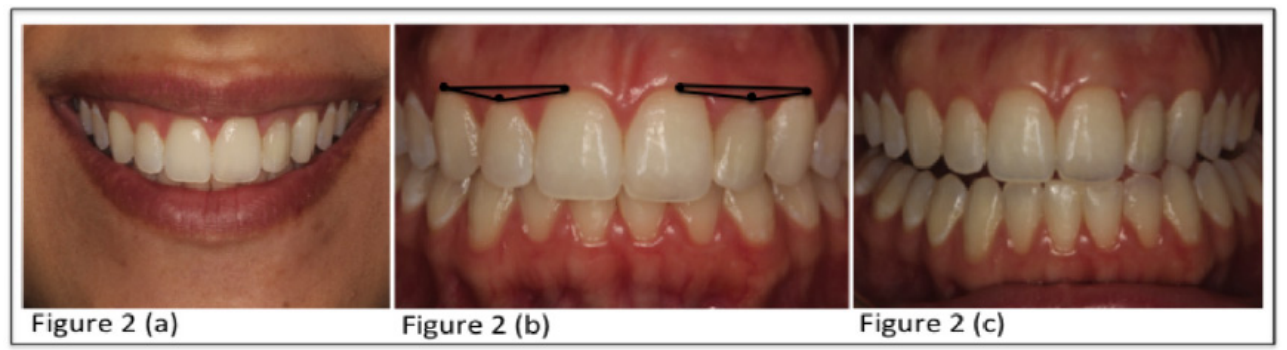

Fig. (2). Patient with agenesis of the left maxillary lateral incisor treated with implant replacement after 3 years: (a) The smile aspect of the patient; (b) The gingival zenith is in agreement with the esthetic pattern proposed in the literature, below of the reference line. Moreover, the gingival zenith in the left size is in symmetry with the gingival zenith of the natural contralateral incisor; (c): The functional aspect of the treatment, showing canine disclusion.

as the type of platform or abutment, the relationship between implant and adjacent teeth, the location of the implant/abutment junction, gingival biotype, among others [60]. As a result, implant crown height may not always be reestablished proportionally to the width of the agenesis area $[39,40]$. Although MLIA patients treated with implants present narrower teeth, it has been reported that they finish their treatment with a more proportional smile than patients treated with canine recontouring, closer to the Golden Proportion [40].

Recently, De-Marchi et al. (2014) found no differences between laypersons and dentists evaluations of the smile of patients treated either with implants or tooth recontouring in comparison with healthy controls [45]. According to the authors, the result indicated that both treatments were capable of achieving esthetic results similar to the untreated dentition. However, some authors have suggested that some aspects such as infra-occlusion of the implant, loss of papilla, and color changes can affect the perception of smile attractiveness over time $[1,56,61]$.

\section{CONCLUSION}

This narrative review summarized the most significant parameters involved with two of the main and wellestablished treatment options for patients with the congenital absence of maxillary lateral incisors, and discussed their indications and limitations. It is not possible to assert at this point in time that one treatment approach is more advantageous than the other. Long-term follow-up studies comparing the existing treatment options are still lacking in the literature, and they are necessary to shed some light on the issue. It is possible, however, to state that adequate multidisciplinary diagnosis and planning is imperative to define the treatment option that will provide the best individual results for patients with MLIA.

\section{CONFLICT OF INTEREST}

The authors confirm that this article content has no conflicts of interest.

\section{ACKNOWLEDGEMENTS}

The authors would like to thank Mr. Antonio Carlos Correa for his contribution with the English version of this paper.

\section{REFERENCES}

[1] Robertsson S, Mohlin B. The congenitally missing lateral incisor. A retrospective study of orthodontic space closure versus restorative treatment. Eur J Orthod 2000; 22: 697-710.

[2] Fekonja A. Hypodontia in orthodontically treated children. Eur J Orthod 2005; 27: 457-60.

[3] Kavadia S, Papadiochou S, Papadiochos I, Zafiriadis L. Agenesis of maxillary lateral incisors: A global overview of the clinical problem. Orthodontics (Chic) 2011; 12: 296-317.

[4] Fujita Y, Hidaka A, Nishida I, Morikawa K, Hashiguchi D, Maki K. Developmental anomalies of permanent lateral incisors in young patients. J Clin Pediatr Dent 2009; 33: 211-15.

[5] Altug-Atac AT, Erdem D. Prevalence and distribution of dental anomalies in orthodontic patients. Am J Orthodont Dentofacial Orthop 2007; 131: 510-4

[6] Polder BJ, Van't Hof MA, Van der Linden FP, Kuijpers-Jagtman AM. A meta-analysis of the prevalence of dental agenesis of permanent teeth. Commun Dent Oral Epidemiol 2004; 32: 217-26.

[7] De Coster PJ, Marks LA, Martens LC, Huysseune A. Dental agenesis: Genetic and clinical perspectives. J Oral Pathol Med 2009; 38 : $1-17$.

[8] Schalk-van der Weide Y, Steen WH, Bsman F. Distribution of missing teeth and tooth morphology in patients with oligodontia. ASDC J Dent Child 1992; 59(2): 33-140.

[9] Chung CJ, Han JH, Kim KH. The pattern and prevalence of hypodontia in Koreans. Oral Dis 2008; 14: 620-5.

[10] Näsman M, Forsberg C-M, Dahllöf G. Long-term dental development in children after treatment for malignant disease. Eur J Orthod 1997; 19: 151-9.

[11] Arte S, Nieminen P, Pirinen S, Thesleff I, Peltonen L. Gene defect in hypodontia: exclusion of EGF, EGFR, and FGF-3 as candidate genes. J Dent Res 1996; 75: 1346-52.

[12] Araújo EA, Oliveira DS, Araújo MT. Diagnostic protocol in cases of congenitally missing maxillary lateral incisors. World J Orthod 2006; 7: 376-88.

[13] Nunn JH, Carter NE, Gilligrass TJ. The interdisciplinary management of hypodontia: Background and role of paediatric dentistry. Br Dent J 2003; 194: 245-51.

[14] Kinzer GA, Kokich Jr VO. Managing congenitally missing lateral incisors part 1: canine substitution. J Esthet Restor Dent 2005; 17 : $5-10$.

[15] Kinzer GA, Kokich Jr VO. Managing Congenitally Missing Lateral Incisors Part 2: Tooth-supported restorations. J Esthet Restorat Dent 2005: 17: 76-84.

[16] Sabri R. Management of missing lateral incisors. J Am Dent Assoc 1999; 130: 80-4.

[17] McNeill RW, Joondeph DR. Congenitally absent maxillary lateral incisors: treatment planning considerations. Angle Orthod 1973; 43: $24-9$

[18] De-Marchi LM, Pini NIP, Hayacibara PM, Silva RS, Pascotto RC. Congenitally missing maxillary lateral incisors: Functional and periodontal aspects in patients treated with implants or space closure and tooth re-contouring. Open Dent J 2012; 6: 248-54.

[19] Pinho T, Lemos C. Dental repercussions of maxillary lateral incisors agenesis. Eur J Dent 2012; 34: 698-703.

[20] Antonarakis GS, Prevezanos P, Gavric J, Christou P. Agenesis of maxillary lateral incisor and tooth replacement: Cost-Effectiveness 
of different treatment alternatives. Int J Prosthodont 2014; 27: 25763.

[21] Andrade DC, Loureiro CA, Araújo VE, Riera R, Atallah AN. Treatment for agenesis of maxillary lateral incisors: a systematic review. Orthod Craniofac Res 2013; 16: 129-36.

[22] Kokich VO, Kinzer GA, Janakievski J. Congenitally missing maxillary lateral incisors: Restorative replacement. Am J Orthod Dentofac Orthoped 2011; 139: 435-45.

[23] Al-Anezi SA. Orthodontic treatment for a patient with hypodontia involving the maxillary lateral incisors. Am J Orthod Dentofac Orthoped 2011; 139(5): 690-7

[24] Mirabella AD, Kokich VG, Rosa M. Analysis of crown widths in subjects with congenitally missing maxillary lateral incisors. Eur J Orthod 2012; 34: 783-7.

[25] Fekonja A. Comparison of mesiodistal crown dimension and arch width in subjects with and without hypodontia. J Esthet Restor Dent 2013; 25(3): 203-10.

[26] Turpin LT. Treatment of missing lateral incisors. Am J Orthod Dentofac Orthoped 2004; 125: 129.

[27] Brough E, Donaldson AN, Naini FB. Canine substitution for missing maxillary lateral incisors: The influence of canine morphology, size, and shade on perceptions of smile attractiveness. Am J Orthod Dentofac Orthoped 2010; 138: 705.e1-9; discussion 705-7.

[28] Tuverson DL. Orthodontic treatment using canines in place of missing maxillary lateral incisors. Am J Orthod 1970; 58: 109-27.

[29] Pini NP, De-Marchi LM, Girardi AR, Pascotto RC. Space Closure and Tooth Re-Contouring in Patients with Congenitally Missing Maxillary Lateral Incisors: Case Report. Int J Clin Dent 2014; In Press.

[30] Rosa M, Zachrisson BU. Integrating esthetic dentistry and space closure in patients with missing maxillary lateral incisors. J Clin Orthod 2001; 35: 221-34.

[31] Senty EL. The maxillary cuspid and missing lateral incisors: Esthetics and occlusion. Angle Orthod 1976; 46: 365-71.

[32] Balshi TJ. Osseointegration and orthodontics: modern treatment for congenitally missing teeth. Int J Period Rest Dent 1993; 13: 494505 .

[33] Telles D, Pegoraro LF, Pereira JC. Prevalence of noncarious cervical lesions and their relation to occlusal aspects: A clinical study. $\mathrm{J}$ Esthetic Dent 2000; 12: 10-5.

[34] Droukas B, Lindée C, Carlsson GE. Relationship between occlusal factors and signs and symptoms of mandibular dysfunction. A clinical study of 48 dental students. Acta Odontol Scand 1984; 42: 277-83.

[35] Grippo JO. Abfractions: a new classification of hard tissue lesions of teeth. J Esthet Dent. 1991; 3: 14-9.

[36] Nordquist GC, McNeill RW. Orthodontic vs. restorative treatment of the congenitally absent lateral incisor - longterm periodontal and occlusal evaluation. J Periodontol 1975; 46: 139-43.

[37] Park JH, Okadakage S, Sato Y, Akamatsu Y, Tai K. Orthodontic treatment of a congenitally missing maxillary lateral incisor. J Esthet Restor Dent 2010; 22(5): 297-312.

[38] Kahn J, Tallents RH, Katzberg RW, Ross ME, Murphy WC. Prevalence of dental occlusal variables and intra-articular temporomandibular disorders: Molar relationship, lateral guidance, and nonworking side contacts. J Prosthet Dent 1999; 82: 410-5.

[39] Pini NP, De-Marchi LM, Gribel BF, Ubaldini ALM, Pascotto RC. Analysis of the golden proportion and width/height ratios of maxillary anterior dentition in patients with lateral incisor agenesis. J Esthet Restor Dent 2012; 24: 402-14.

[40] Pini NP, De-Marchi LM, Gribel BF, Pascotto RC. Digital analysis of anterior dental esthetic parameters in patients with bilateral maxillary lateral incisor agenesis. J Esthet Restor Dent 2013; 25: 189200.

[41] Armbruster PC, Gardiner DM, Whitley Jr JB, Flerra J. The congenitally missing maxillary lateral incisor. Part 2: assessing dentists' preferences for treatment. World J Orthod 2005; 6: 376-81.

[42] Van der Geld P, Oosterveld P, Van Heck G, Kuijpers-Jagtman AM. Smile attractiveness. Angle Orthod 2007; 77: 759-65.
[43] Pini NIP, De-Marchi LM, Gribel BF, Ramos AL, Furquim LZ, Pascotto RC. Analysis of width/heigth ratio and gingival zenith in patients with bilateral agenesis of maxillary lateral incisors. Dental Press J Orthod 2012; 17: 87-93.

[44] Zachrisson BU1, Rosa M, Toreskog S. Congenitally missing maxillary lateral incisors: canine substitution. Point. Am J Orthod Dentofac Orthoped 2011; 139(4): 434, 436, 438 passim.

[45] De-Marchi LM, Pini NIP, Ramos AL, Pascotto RC. Smile attractiveness of patients treated for congenitally missing maxillary lateral incisors as rated by dentists, laypersons, and the patients themselves. J Prosthet Dent 2014; 112(3): 540-6.

[46] Pinho T, Bellot-Arcís C, Montiel-Company JM, Neves M. Esthetic assessment of the effect of gingival exposure in the smile of patients with unilateral and bilateral maxillary incisor agenesis. $J$ Prosthodont 2014. doi: 10.1111/jopr.12216. [Epub ahead of print].

[47] Rosa M, Olimpo A, Fastuca R, Caprioglio A. Perceptions of dental professionals and laypeople to altered dental esthetics in cases with congenitally missing maxillary lateral incisors. Prog Orthod 2013; 14: 34 .

[48] Avila ED, Molon RS, Mollo-Junior FA, Barros LAB, CapelozzaFilho L, Cardoso MA, Cirelli JA. Multidisciplinary approach for the aesthetic treatment of maxillary lateral incisors agenesis: thinking about implants? Oral Surg Oral Med Oral Pathol Oral Radiol 2012; 114: e22-8.

[49] Jackson BJ, Slavin MR.Treatment of congenitally missing maxillary lateral incisors: an interdisciplinary approach. J Oral Implantol 2013; 39(2): 187-92

[50] Kinzer GA, Kokich Jr VO. Managing Congenitally Missing Lateral Incisors Part III: single-tooth implants. J Esthet Rest Dent 2005; 17: $202-10$

[51] Nováčková S, Marek I, Kaminek M. Orthodontic tooth movement: bone formation and its stability over time. Am J Orthod Dentofacial Orthop 2011; 139: 37-43.

[52] Thilander B, Odman J, Lekholm U. Orthodontic aspects of the use of oral implants in adolescents: a 10-year follow-up study. Eur J Orthod 2001; 23: 715-31.

[53] Krassnig M, Fickl S. Congenitally missing lateral incisors--a comparison between restorative, implant, and orthodontic approaches. Dent Clin North Am 2011; 55: 283-99.

[54] Kokich VG. Maxillary lateral incisor implants: Planning with the aid of orthodontics. J Oral Maxillofac Surg 2004; 62: 48-56.

[55] Uribe F, Padala S, Allareddy V, Nanda R. Cone-beam computed tomography evaluation of alveolar ridge width and height changes after orthodontic space opening in patients with congenitally missing maxillary lateral incisors. Am J Orthod Dentofac Orthoped 2013; 144: 848-59.

[56] Chang M, Wennström JL, Odman P, Andersson B. Implant supported single-tooth replacements compared to contralateral natural teeth. Crown and soft tissue dimensions. Clin Oral Impl Res 1999; 10: $185-94$.

[57] Bengazi F, Wennström JL, Lekholm U. Recession of the soft tissue margin at oral implants. A 2-year longitudinal prospective study. Clin Oral Implants Res 1996; 7: 303-10.

[58] Marchi LM, Pini NI, Hayacibara RM, Silva RS, Pascotto RC. Congenitally missing maxillary lateral incisors: functional and periodontal aspects in patients treated with implants or space closure and tooth re-contouring. Open Dent J 2012; 6: 248-54.

[59] Rodriguez-Ciurana X, Vela-Nebot X, Segala-Torres M, et al. The effect of interimplant distance on the height of the interimplant bone crest when using platform-switched implants. Int J Periodontics Restorative Dent 2009; 29: 141-51.

[60] Cappiello M, Luongo R, Di R, et al. Evaluation of peri-implant bone loss around platform-switched implants. Int J Periodontics Restorative Dent 2008; 28: 346-55.

[61] Thordarson A, Zachrisson BU, Mjör IA. Remodeling of canines to the shape of lateral incisors by grinding: A long-term clinical and radiographic evaluation. Am J Orthod Dentofac Orthoped 1991; 100: $123-32$

\section{Received: October 25, 2014 \\ (C) Pini et al.; Licensee Bentham Open.}

Revised: December 09, 2014

Accepted: December 19, 2014

This is an open access article licensed under the terms of the Creative Commons Attribution Non-Commercial License (http://creativecommons.org/licenses/by-nc/3.0/) which permits unrestricted, non-commercial use, distribution and reproduction in any medium, provided the work is properly cited. 